\title{
Web 2.0 Applications in China
}

\author{
Dongsheng Zhai ', Chen Liu ${ }^{2}$ \\ School of Economics and Management, Beijing University of \\ Technology, Beijing, China, 100022 \\ I zhaidongsheng@bjut.edu.cn \\ 2 bill1130@gmail.com
}

\begin{abstract}
Since 2005, the term Web 2.0 has gradually become a hot topic on the Internet. Web 2.0 lets users create web contents as distinct from webmasters or web coders. Web 2.0 has come to our work, our life and even has become an indispensable part of our web-life. Its applications have already been widespread in many fields on the Internet. So far, China has about 137 million netizens [1], therefore its Web 2.0 market is so attractive that many sources of venture capital flow into the Chinese Web 2.0 market and there are also a lot of new Web 2.0 companies in China. However, the development of Web 2.0 in China is accompanied by some problems and obstacles. In this paper, we will mainly discuss Web 2.0 applications in China, with their current problems and future development trends.
\end{abstract}

\section{Introduction}

Web development can be classified in terms of four drivers: First driver: email exchange (Group support: FTP server and email list) in the 1980's. Second driver: passive web pages (Electronic \& image publishing, access to remote services) in the 1990's. Third driver: P2P (Communities of exchange of music, movies, files, etc) in the late 1990's. Fourth driver: Blogs (Universe of syndicated diaries) in the 2000's. The Blog is also the main application representative of Web 2.0.

The creator of World Wide Web (WWW), Tim Berners-Lee [2] once talked about WWW: "There was a second part of the dream... we could then use computers to help us analyze it, make sense of what we' re doing, where we individually fit in, and how we can better work together." As a matter of fact, Web 2.0 has become more and more similar to what he said.

Since 2005, Web 2.0 has become a buzzword on the Internet. A great number of Web 2.0 applications appeared suddenly in a short time, Blog, Wiki, RSS and so on. In particular, the search engine giant Google developed several innovative Web 2.0

Please use the following format when citing this chapter:

Zhai, D., I.iu, C., 2007, in IFIP International Federation for Information Processing, Volume 252, Integration and Innovation Orient to E-Socicty Volume 2, eds. Wang, W., (Boston: Springer), pp. 26-33. 
applications at this time, such as Google Maps and Google Mail. Almost every netizen was attracted by the colorful and personalized interfaces, various and useful functions and more interactive approaches with the Web from those applications. In a sense, Google promoted the influence and development of Web 2.0. Therefore, more Web 2.0 applications and Web 2.0 companies emerged. The core spirit of Web 2.0 is: Open, Shared, Communication and Growing-up together, which has been an inspiration to everyone.

China has a large number of netizens. Therefore, many sources of venture capital poured into Chinese Web 2.0 market at the beginning of Web 2.0 development. Certainly, many Web 2.0 companies in China started their dreams at that time. Almost everyone wants to be the second Flickr or YouTube, two famous Web 2.0 websites recently bought by Yahoo and Google respectively, but the ideal is often contrary to the reality. A very small number of them gain success from Web 2.0.

The rest of the paper is organized as follows. In section 2, we will briefly introduce some concepts of Web 2.0. Section 3 discusses Web 2.0 applications in China, including its history, current problems and future development trends. Section 4 is the conclusion.

\section{Web 2.0}

\subsection{What is Web 2.0?}

The concept of Web 2.0 was presented during a conference brainstorming session between O'Reilly [3] and MediaLive International in October 2004. Later, by the efforts of Tim O'Reilly and his partners, the Web 2.0 Conference was held to continue discussions further. Today, there are about 4.1 million hyperlinks relevant to Web 2.0 in Google.com.

In order to understand what Web 2.0 is, we firstly should learn what Web 1.0 is. Web between 1993 and 2003 is regarded as Web 1.0, and the Web since 2003 is socalled Web 2.0. Web 1.0 are mostly HTML pages viewed through a Web browser, while Web 2.0 are web pages, plus a lot of other "content" shared over the web, with more interactivity. This is more like an application than a "page". Users may create the contents of web rather than just web coders. They are no longer restricted within the fixed and rigid pages' contents without any users' interaction. In other words, users' participation is the core of Web 2.0.

Jim Cuene analyzed the differences between Web 1.0 and Web 2.0 incisively in his speech "Web 2.0: Is it a whole new Internet?" [4].

Table 9. The differences between Web 1.0 and Web 2.0 presented by Jim Cuene

\begin{tabular}{|c|c|c|}
\hline Web 1.0 & Web 2.0 \\
\hline "Read" & Mode & "Write" \& Contribute \\
\hline "Page" & Primary Unit of content & "Post / record" \\
\hline "static" & State & "dynamic" \\
\hline
\end{tabular}




\begin{tabular}{|c|c|c|}
\hline Web browser & Viewed through... & Browsers, RSS Readers, anything \\
\hline "Client Server" & Architecture & "Web Services" \\
\hline Web Coders & Content Created by... & Everyone \\
\hline "geeks" & Domain of... & "mass amateurization" \\
\hline
\end{tabular}

We can say Web 2.0 is the symbol of the second revolution and release of web technology. Of course, Web 2.0 also provides us with more creative and personalized web applications.

In conclusion, Web 2.0 is not just a simple update of Web 1.0, but brings great innovation in technology and creative notions in people's minds.

\subsection{Main technology of Web 2.0 - Ajax}

When we refer to Web 2.0 technologies, we have to mention AJAX, one of core technologies of Web 2.0. AJAX is an acronym for Asynchronous JavaScript and $\mathrm{XML}$. It isn't a new technology, but a combination of certain technologies in order to realize their respective function under the collaboration.

As Jesse James Garrett [5] (the presenter of Ajax) explained, Ajax includes following aspects:

- standard-based presentation using XHTML and CSS

- dynamic display and interaction using the Document Object Model

- data interchange and manipulation using XML and XSLT

- asynchronous data retrieval using XMLHttpRequest

- And Javascript binding everything together

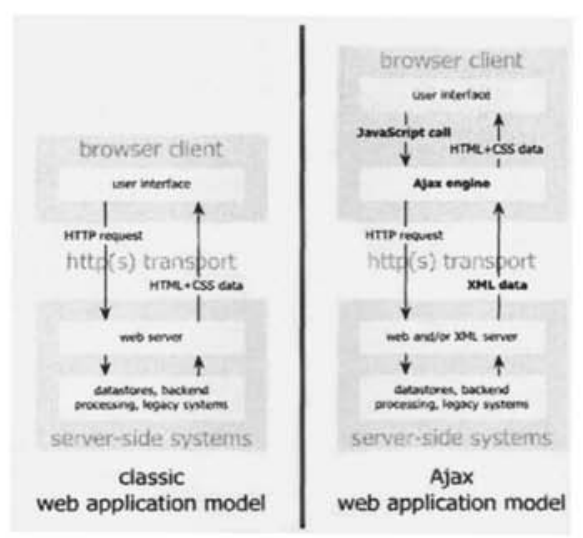

Fig. 9. Comparison of classic and Ajax web application model

From the pictures above, a traditional web application is always submitted from the client browser to the server, the server returns the new pages and these pages display in the browser again, which mean that each data travel needs to update the browser pages. 
Ajax application changes this pattern. The Ajax Engine written in Javascript takes on the middle-level tasks in the Ajax application. When users submit data to the server, Ajax is responsible for collecting data and sending them to the server by Http Request (XMLHttpRequest). It returns XML after processing in the server. The Ajax Engine processes XML in order to display XHTML and CSS data in the users' interfaces and update the corresponding parts of the presentation, rather than refreshing the entire pages, so it avoids unnecessary data travel and only necessary data are transmitted in the necessary time between browser and server.

Because Ajax undertakes the tasks of communication with the server, it makes possible that web browsing and interactions between applications are processed in asynchronous mode. The asynchronous mode allows users never to be faced up with blank screen and so users can't continue their own jobs until the processing of the server is completed. Ajax technology lets web applications have similar users' experiences with desktop applications and improves the usability of web applications. In a sense, we can say that it produces the most distinct advantage and improvement between Web 1.0 and Web 2.0 .

\subsection{Some Web 2.0 Applications}

\section{B $\log$}

Blog is the abbreviation for "Web Blog". It is a personal log in chronological order, updated at regular intervals as users wish. Users can put their own pictures, diaries, and even ideas on their Blogs, which can be scanned by other people. Visitors are allowed to leave comments for the authors [6-8].

\section{Wikipedia}

This is an online encyclopedia, created and supported by its users. In the latest data report issued by comScore Networks, a marketing research company, Wikipedia has become one of the top 10 hot websites in the United States, which exceeds the New York Times and Apple. While in the worldwide, Wikipedia has already been one of the top 10 hot websites for a long time.

\section{RSS}

RSS means Really Simple Syndication, which is a format of description and synchronization of website contents. It provides a technical platform for transmitting information rapidly. As long as you are subscribed to the contents of certain web pages you need in the RSS reader, the latest updated contents will be sent to your RSS reader in time. Then you may look at them in the RSS reader directly instead of turning to the pages and refreshing them by yourself.

SNS

SNS stands for Social Network Software. In terms of the Six Degrees of Separation Theory, we can know each person throughout the world only by knowing six persons directly. Therefore, SNS is exactly an effective way to expand one's circle of friends.

Tag

In short, Tag allows us to name something on the Internet, such as photos, diaries, with meaningful names. It permits systems to search the results in a natural way appropriate to each user. 


\section{Web 2.0 applications in China}

\subsection{The history of Web 2.0 applications in China}

As the biggest developing country, China has attracted many sources of venture capital in various markets. According to statistics, the total number of netizens in China has reached 137 million nowadays. Therefore, Internet is also a "battle" for them. The most significant characteristic for Web 2.0 is users' participation. Internet is not the Internet as it was 10 years ago. It allows users to design modes, contents and other aspects of the web. In China, there exists some successful Web 2.0 websites, such as Mop.com and Douban.com. They are the leading strength of Web 2.0 in China. Users may taste Web 2.0 and learn more about Web 2.0 from these websites.

As for Web 2.0 applications, such as Blog, have been gradually given more attentions since 2002. Fang Xingdong and Wang Junxiu set the Chinese name of Blog as "Bo Ke". In August, 2002, they created the first Chinese Blog website, that is, www.blogchina.com. Since 2005, Blog application in China has developed rapidly. In terms of data issued by CNNIC in July, 2006 [9], among the netizens in China, Blog users are 17.5 million, active Blog users are 7.7 million and Blog readers are 75 million. In contrast, the number of netizens in America who read Blog is about 57 million, which occupies $37 \%$ of the netizens in America [10].

Compared with Blog, the development of Wiki in China is rather slow. Although there are some Wiki websites, such as www.wikicn.com and www.wikilib.com, their impacts and the number of users are limited. In China, RSS application started in March, 2004. Many websites, such as China Blog, XinHua Net and Sina, published their own RSS Aggregation News services and developed RSS readers. At present, most News websites have provided RSS services, which are also embedded in Blog.. Users can gain great conveniences from RSS. As for Tag and SNS, several websites provide such applications. However, to some extent their influences are limited and Chinese netizens know little about them in general. Compared with China, the proportion of netizens in America who use Tag is about 30\%. MySpace, the biggest SNS website in America, was bought by Murdoch with 850 million dollars in 2005 and its click rate has already exceeded Yahoo and Google now.

\subsection{The current problems of Web 2.0 applications in China}

Compared with the situation in 2005, tremendous changes have occurred in Chinese Web 2.0 market nowadays. The turnings of venture capital, the reducing of the staff and the closing down of some Web 2.0 companies are also the harmful factors for the development of Web 2.0 industry in China.

In China, there are so many Web 2.0 companies providing parallel applications and services that the creativeness and individuation of web pages and the quality of services can't be ensured and satisfied. For example, many websites provide Blog services, but their services are almost the same and haven't any innovation, which can't attract most netizens to access the same function and service of different websites. It may not be good that many people do the same thing. 
Yahoo recently bought Flickr, while Google acquired YouTube with 1.65 billion dollars. Both Flickr and YouTube are Web 2.0 companies. By providing personalized contents, friendly users' experiences and innovative services, they have millions of registered users around the world. In China, thousands of Web 2.0 companies appeared in 2005, but in the Web 2.0 wave of China, the winners like Flickr and YouTube are extremely the few. Many new web companies paste the label of Web 2.0 on themselves in order to attract more users and more sources of venture capital. However, unfortunately, many of them go bankrupt after a short time. There are a lot of reasons for that. Perhaps, the most important factor is that those companies only focus on the presentations of Web 2.0 and claim themselves to be Web 2.0 websites by just providing some Web 2.0 applications. In fact, they don't really know the true essence of Web 2.0 . Web 2.0 is more like an idea or a concept. The main principle of Web 2.0 is users' participation. That is, companies should have the idea that users are the creator of web contents. Therefore they should make efforts to provide really open environments for users' interaction and let them easily enjoy the advantages and conveniences of Web 2.0. However, many companies try hard to gain business chances firstly and only focus on temporary profits. Providing services for users is just a mask for them. Sometimes, they may hurt the users for the sake of their own temporary profits.

Compared with America, China has some disadvantages in Web 2.0. For example, although China has about 137 million netizens, the popularity of netizens in China stands at less than $10 \%$, while the popularity of netizens in America is more than $70 \%$. Furthermore, the principle of Web 2.0 is users' participation, so higher requirements to netizens are needed. However, most of Chinese netizens are preliminary and less-educated. Besides, the success of Web 2.0 companies in America, such as YouTube, partly attributes to wise and brave venture capital. Those sources of venture capital give Web 2.0 more and more supports. Therefore they also promote the healthy and steady development of Web 2.0 in America. On the contrary, in China many sources of venture capital lack courage and insight and they are easily prone to follow others. On the other hand, Web 2.0 has something with economy and culture in society. For example, the popularity of camera equipments in China is far less than in America. Hence, some video-share companies, such as YouTube, may succeed in America, while in China such companies may encounter much more obstacles and difficulties.

\subsection{The development trends of Web 2.0}

Although there are many problems and obstacles for the development of Web 2.0 in China, some sources of venture capital still flow into certain Web 2.0 companies. For example, Mop.com gained about 48 million dollars from American Venture Capital Corporation and General Atlantic last year. After that, Sequoia Capital, Redpoint Ventures and Highland Capital Management Corporation invested 25 million dollars in Qihoo, a company specialized in Blog search. In conclusion, Web 2.0 market in China is still attractive to venture capital, but they are more rational than ever before.

Web 2.0 emphasizes users' interaction, because the service object of Internet should be users not webmasters or web coders. That is, let the users, the receiver of contents in the web, become the creator and provider of contents at the same time. 
Because only the users know the contents what they really want to gain exactly from the web.

The Long Tail Theory [11] put emphasis on the pursuit of so-called long tail. As for Web 2.0, "the long tail" is that the better personalized services you provide, the more likely you succeed. Web 2.0 has many advantages over Web 1.0 and it offers a large scope of profits. The key is whether you can grasp them. Only by paying more attentions to users' requirements and providing more attractive and personalized services, Chinese Web 2.0 companies can exist longer and make more profits. It is an extremely good advantage that China has a great number of netizens. The current problem is how to attract them to access Web 2.0 websites and let them enjoy in those websites. Some websites, such as Sina.com, Mop.com and Douban.com have exploited the road for us. They provide good Web 2.0 applications with friendly users' experiences and really open environments for users' interaction. Therefore, as long as other companies can understand the true essence of Web 2.0, learn much more valuable things from those good examples and create their own predominances, they may win the users and the Web 2.0 market. Maybe the next YouTube or Flickr will be in China in the near future.

\section{Conclusion}

We have experienced the Internet bubble a few years ago, while we are facing up with a new era of web or just another Internet bubble. Web 2.0 has brought us with many creative technologies and personalized web applications. User's participation is the main principle of Web 2.0. Users become the creator of web contents instead of webmasters or web coders. As for Web 2.0 companies in China, Web 2.0 is not only an opportunity, but also a challenge. Although there are many problems and obstacles during the development of Web 2.0 in China, Chinese netizens and Web 2.0 companies are still making efforts in this road. Whether they can gain a result of win-win is depending on their endeavors and contributions in the future.

\section{References}

1. China Internet Network Information Center(CNNIC), China Internet Development Statistics Report, January 23, 2007

2. Hak Lae Kim, Towards the Semantic Web 2.0, 2005

3. Tim O'Reilly, What is Web 2.0: Design Patterns and Business Models for the Next Generation of Software, September 30, 2005

4. Jim Cuene, Web 2.0: Is it a whole new internet?, May 18, 2005

5. Jesse James Garrett, Ajax: A New Approach to Web Applications, February 18, 2005

6. Tang Dailu, The transformation of Internet: Web 2.0 ideas and design, January 1,2007

7. David Best, Web 2.0: Next Big Thing or Next Big Internet Bubble?, January 11, 2006 
8. Win Treese, Web 2.0: Web 2.0: Is it really different?, June, 2006

9. China Internet Network Information Center(CNNIC), 2006 Chinese Blog Survey Report, September 23, 2006

10. Pew Internet \& American Life Project, Bloggers-A portrait of the internet's new storytellers, July 19, 2006

11. Chris Anderson, The Long Tail (China CITIC Press, December, 2006) 